Journal of Information Systems and Technology Management - Jistem USP

Vol. 15, 2018, e201815010

ISSN online: $1807-1775$

DOI: $10.4301 / \mathrm{S} 1807-1775201815010$

\title{
RESEARCH METHODOLOGY FOR NOVELTY TECHNOLOGY
}

P C, Lai, https://orcid.org/0000-0002-8319-8459

ELM Graduate School, Help University, Malaysia

\begin{abstract}
This paper contributes to the existing literature by reviewing the research methodology and relevant literature with the focus on potential applications for the novelty technology of the single platform Epayment. The review includes subjects, populations, sample size requirement, data collection methods and measurement of variables, pilot study and statistical techniques for data analysis used in past researches. The review will shed some light and potential applications for future researchers, students and others to conceptualize operationalize and analyze the underlying research methodology in the development of their research for novelty technology.
\end{abstract}

Keywords: Research Methodology; Single Platform E-payment; Sample Size, Structural Equation Model, Data Analysis

JEL: C12; C18; C30; C39; C83; C89; M10; M15; M31; O32

Manuscript first received 2018-04-04. Manuscript accepted: 2018-08-14

Address for correspondence:

PC, Lai, ELM Graduate School, Help University, Malaysia

E-mail: pcresearch8@gmail.com 


\section{INTRODUCTION}

The research methodology for novelty technology of the "single platform E-payment System" is reviewed in this article and provides the details of research instrument development for this novelty technology (Lai, 2012; 2014; 2015; 2016; 2018). According to Avison and Fitzgerald (1995), the methodology is based on a philosophical paradigm supported by a compilation of procedures, techniques, tools and documentation aids that will be discussed in this article. This review also discusses the subjects, populations, sample size requirements, data collection methods and measurement of variables, pilot studies and statistical techniques for data analysis from the relevant researches.

\section{RESEARCH STRATEGY}

Positivism is an epistemology position that advocates the applications of the research strategy used in this study. It involves a deductive approach underpinned by the objectivist ontology (Crotty, 1998). The research strategy is vital to any study in order to identify hypotheses and significance to research development (Miller, 1983; Marczyk, DeMatteo and Festinger, 2005; Bryman and Bell, 2007).

Yin (2002) identifies the main research methods include surveys and experiments as primary research as well as archival analysis and case studies as secondary research. Methods used include library research, field work, interviews, surveys, observation, evaluation, and analysis. There are some secondary data being discussed in this paper. Because of the limitation of the secondary data, primary research using quantitative method is chosen in this study.

The aim of the present study was to examine the relationships between perceived ease of use, perceived usefulness and perceived risk with consumers' intention to use the novelty single platform E-payment (Lai, 2014; 2016; 2017; Lai and Zainal, 2014; 2015). Based on the scientific or positivistic paradigm, the quantitative research method was used in this study to explain these relationships, test the theory, describe the patterns, and measure the consumers' intention to use (Cooper and Schindler, 2008). Therefore, the research strategy uses the deductive process, going from generalizations (theory) leading to prediction (hypotheses), explanation, and understanding the consumers' intention to use the novelty single platform E-payment. This research is explanatory whereby the research questions and hypotheses are poised to explain the phenomena under the investigation. The research strategy process used in this study is shown in Figure 1.

\section{RESEARCH DESIGN}

The research project to examine and attain answers to the proposed research questions guided through a plan is known as research design (Saunders, Lewis, \& Thornhill, 2012). According to Cooper and Schindler (2008), the three types of research designs are exploratory, descriptive, and causal or explanatory. Neuman (2006) indicated that exploratory research involved an attempt to explore and generate new ideas and themes that provided the prerequisite for further research. 
In this study, the relationship between variables of the hypothesized model will be discussed as part of the explanatory research design. As suggested by Churchill, 1979; Sekaran (2003); Bryman and Bell (2007); Lai (2014; 2016); Lai and Zainal (2014; 2015); the hypotheses were generated after a thorough investigation of the literature and the background information search and the research

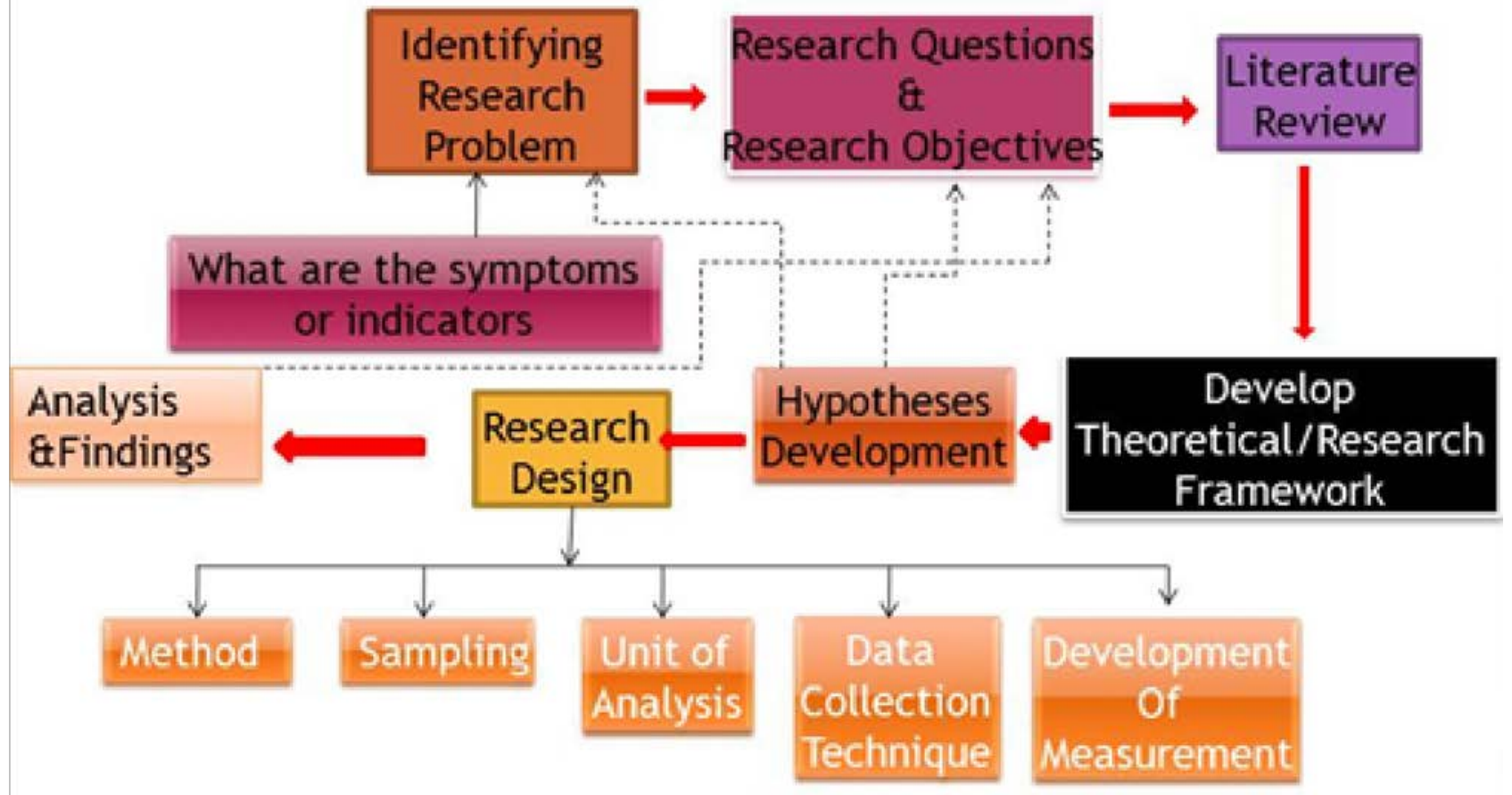

Figure 1. Research Strategy Process

Source:. Sekaran (2003); Bryman and Bell (2007); Lai (2014; 2016); Lai and Zainal (2014; 2015)

problems identified. The next stage involves questionnaires design, pilot test, and data collection. . After data collection, the descriptive research design is used for analysis in order to determine the mean, standard deviation, frequencies, and percentages as well as to explain the respondents' characteristics..

\section{Target Population and Sample}

The target population and sample in this study has been discussed earlier by Lai and Zainal (2015). The study involves surveying current users of Internet or/and mobile who use E-payment in Malaysia. Those who choose to use E-payment systems will be able to provide more realistic feedback on their personal experiences with regard to their intention to use the novelty single platform Epayment. Malaysian Internet users have reached 17.5 million with 5 million broadband users, 2.5 million wireless broadband users and 10 million 3G subscribers while Touch n Go has 10 million subscribers (Lai; 2014). The mobile phone subscribers (total of 3 major providers Maxis, Celcom Axiata and Digi already more than 32 million) and bank card subscribers (e.g: 34 million for debit card based on Bank Negara report 2011) have already exceeded the number of population (28.3 
Lai, P.C.

million based on Malaysian Statistic report 2010) in Malaysia. Nevertheless, there are people owning more than one phone SIM as well as more than one bank cards. Bank Negara report 2011 released the figures for Internet banking subscribers (34.4\% for Individual users in 2010 of the population) and mobile banking subscribers (3\% Mobile penetration rate in 2010 against population).

The statistics did not take into account the number of foreigners in the country as the statistics only showed a number of subscribers. These figures show that there is high ownership of payment devices and banking E-payment subscribers that allow users to make E-payment, but the actual number of users of E-payment systems is not known. As such, this study falls under non-probability sampling; thus, purposive sampling was selected since the target users were those using the Internet or/and Mobile for E-payment for the last one year.

\section{Sample Size}

By using the ratio of 10:1 as suggested by Kline (2011), the sample size was based on the total number of items used in the questionnaires. The sample size met the requirements of the technique used to analyze the data based on Kline (2011). Therefore, using the ratio 10:1 and nonprobability sampling, the minimum recommended sample size was 440 (Lai and Zainal, 2015).

\section{Unit of Analysis}

Neuman (2006) noted that the type of unit the researcher used to measure the variables was indicated as a unit of analysis. This researcher seeks to investigate the factors that influence perceived ease of use and perceived usefulness of the novelty single platform E-payment system. Further, the researcher is interested to investigate the relationship between perceived ease of use, perceived usefulness and perceived risk with consumers' intention to use one (1) single platform that integrates Card, Internet, and Mobile are known as "the novelty single platform E-payment". Hence, the unit of analysis chosen for this study was the consumers who owned at least one (1) of the following items (e.g: mobile phone, card payment, internet) and used at least one time for the past 12 months.. This criterion was selected to identify the current users of the E-payment as respondents. Furthermore, this group will be the potential early adopter group of the novelty single platform E-payment.

\section{Data Collection}

This section includes the questionnaire design, data collection method using online research, followed by the sample size selection from the target population. At the time of this research, the novelty single platform E-payment was not yet in the marketplace. Therefore, a video was prepared to illustrate the concept of a single platform E-Payment System. The link to the video and questionnaires using google document were posted on a portal to gather the respondents' feedback. E-mail reminders, Facebook posting to relevant groups, and search engine optimization were used to increase respond rate. The respondents must meet the criteria of having used the Internet or/and Mobile payment for the last one year. A number of measures to produce the questionnaires were engaged to increase the respond rate. Sekaran and Bougie (2013) suggested looking into the wording of the questions and the appearance of the questionnaires. The process of distributing and collecting data took three months. 


\section{Questionnaires}

. The survey is a useful technique to capture facts, opinions, behaviours or attitudes using questionnaires from a range of respondents (Maylor and Blackmon, 2005). These are the preferred choice of research method for this research. Survey method is used to collect the data with the assistance of online research tools. According to Bryman and Bell (2007), the self-administered method has a better advantage than the interview-administered in terms of convenience (time, cost and location for both interviewer and interviewee) as it is less obstructive (absence of interviewer effects) to interviewees. Since there was cost and time constraints, a questionnaire survey was selected as the main empirical data collection method.

In this research, the researcher used the online questionnaire for standard electronic computation as discussed in the choice of research method. The novelty single platform E-payment market audience is the main target for online market research (Lai and Scheele, 2017). Therefore, an online research survey was chosen as the method for this research. The Internet can be accessed either through the mobile phone, the iPad and the PC/notebook as long as there is internet available. Thus, online research provides new opportunities for data collection of the targeted minimum number of respondents according to the number of items multiplied by 10 that fulfill the set requirements. This method was chosen so that data collected was centralized and monitoring can be done any time for further action to respond to specific demographic requirements.

\section{Online Research Survey}

Electronic payment consumers were the target for the online research survey. Online research survey was selected because the consumers who use the internet or/and mobile are accessible online (Lai, 2006; 2007). To encourage responses to the online survey in addition to e-mails blast techniques, Facebook posting and search engine optimization were used. In conventional paper and pencil surveys, one question might be asked if the respondent has used any payment system (card or Internet or Mobile) for the last one year. If the respondent answered "no," to online payment, he or she is asked to skip online payment questions (e.g., going straight to question related to card payment instead of proceeding to Internet payment). If the respondent answered "yes" to Internet payment, he or she is instructed to go to the online payment question which, along with the next several ones, addresses issues related to the Internet payment experience.

Conditional branching allows the computer to skip directly to the appropriate question. If a respondent is asked the types of payment system he or she will consider, it is also possible to add payment system comparison questions to this list. For example, if the respondent considers using cash, card, Internet or mobile payment, it will be possible to ask the respondent questions about his or her view of the relative interest of each respective pair (e.g., in this case type of payment system, cash vs. card, card vs. Internet and card vs. Mobile). Online search data and page visit logs provide further valuable information for analysis of the company website page if this is deemed relevant for this research.

Every method has its disadvantages; so does online research. Some consumers may be more comfortable with online activities than others; furthermore, not everyone will have access. This means our target is people with Internet access only. Today, however, this type of response bias is probably not significantly greater than that associated with other types of research methods. The 
major disadvantage of online research is to get respondents to carefully read instructions and other information online as there is a tendency to move quickly. This makes it difficult to perform research that depends on the respondent's reading of a situation or product description. Therefore, online research questions should be straightforward and directly relevant to the research.

\section{MEASUREMENT OF VARIABLES}

Cox (1980) recommended that the scale points of five should be used depending on the particular environments. Therefore, in this research the five-point scale Likert-type of measuring the consumers' intention to use the novelty single platform E-payment from 1 "strongly disagree" to 5 "strongly agree" were used. When responding to the survey items, participants specify their levels of agreement to a subject given. The five points scale was selected to encourage respondents to make positive or negative choices (Cooper, Schindler, and Sun, 2008) in order to produce more emphatic information, avoiding what Oppenheim (1992) described as a lukewarm response. The following section will explain the measurement of variables as discussed previously in Lai and Zainal (2015).

\section{Design}

In this research, design was operationalized with reference to the technical "design and functionality" of the novelty single platform E-payment. Novelty is in line with the adaptation to consumer's capabilities of using the single novelty single platform E-payment platform system for Card, Internet and Mobile Payment (Szymanski and Hise, 2000). In this study, the measurement of the novelty design of the novelty single platform E-payment in Table 1 was adapted from Szymanski and Hise (2000), Lin and Hsieh (2006) as well as Lai and Zainal (2015) using a five-point Likert scale.

\section{Convenience}

Convenience was operationalized as the novelty single platform E-payment which is easy to use, accessible with multi-functions on the phone, and is in accessible places (Meuter et al., 2000). Convenience of the novelty single platform E-payment single platform E-payment system measurements were adapted from Szymanski and Hise (2000) and Lai (2010) referring to easy to use while accessible with multi-functions on the phone, and in reachable locations from Meuter, Ostrom, Roundtree, \& Bitner (2000). A five-point scale Likert was used in the measurement of convenience in Table 1.

\section{Perceived Usefulness}

Perceived Usefulness was operationalized as the potential user's subjective likelihood that the use of a certain system (e.g: the novelty single platform E-payment) will increase his/her performance (Davis, 1989; Lai (2014: 2016: 2017: 2018). Therefore, the measurement of perceived usefulness is adapted from Maran, Lawrence, Fazilah, Kishna, and Ng (2011), Lai (2014: 2016: 2017: 2018) and Davis (1989) using a 5-point Likert scale in Table 1. 


\section{Perceived Ease of Use}

In this research, Perceived Ease of Use was operationalized as the degree to which the potential user expected the target system (e.g: The novelty single platform E-payment) to be free of effort (Davis, 1989; Lai (2014: 2016: 2017; 2018). Therefore, the measurement of perceived ease of use is adapted from Maran, Lawrence, Fazilah, Kishna and Ng (2011), Lai (2014: 2016: 2017: 2018) and Davis (1989) using a 5-point Likert scale in Table 1.

Table 1. Measurements Used in this Research

\begin{tabular}{|c|c|c|c|c|}
\hline Dimension & Source & Items & Scale & Cronbach's $\alpha$ \\
\hline Design & $\begin{array}{l}\text { adapted from Szymanski and Hise } \\
\text { (2000); Lin and Hsieh (2006); Lai and } \\
\text { Zainal (2015); }\end{array}$ & 8 & $1-5$ & $.69-.75$ \\
\hline Security & $\begin{array}{l}\text { adapted from Polatoglu and Ekin, } \\
\text { (2001), White and Nteli, (2004), } \\
\text { Sumanjeet (2009), Lai, (2013) }\end{array}$ & 6 & $1-5$ & $.68-.82$ \\
\hline $\begin{array}{l}\text { Perceived } \\
\text { Usefulness }\end{array}$ & $\begin{array}{l}\text { adapted from Davis (1989); Maran, } \\
\text { Lawrence, Fazilah, Kishna and } \\
\text { Ng (2011); Lai (2014: 2016: 2017; 2018) }\end{array}$ & 10 & $1-5$ & $.73-.95$ \\
\hline $\begin{array}{l}\text { Perceived Ease of } \\
\text { Use }\end{array}$ & $\begin{array}{l}\text { adapted from Davis (1989); Maran, } \\
\text { Lawrence, Fazilah, Kishna and } \\
\text { Ng (2011); Lai (2014: 2016: 2017; 2018) }\end{array}$ & 10 & $1-5$ & $.73-.91$ \\
\hline Perceived Risk & $\begin{array}{l}\text { adapted from Jarvenpaa, Tractinsky, and } \\
\text { Vitale (2000); Chan and Lu } \\
\text { (2004); Ndubisi and Sinti (2006); } \\
\text { Lai and Zainal (2015) }\end{array}$ & 6 & $1-5$ & $.65-.87$ \\
\hline $\begin{array}{l}\text { Consumers' } \\
\text { Intention to use }\end{array}$ & $\begin{array}{l}\text { adapted from Davis (1989) ; Lai (2014: } \\
\text { 2016: 2017; 2018) }\end{array}$ & 4 & $1-5$ & $.80-.96$ \\
\hline
\end{tabular}

\section{Perceived Risk}

According to Chan and Lu (2004), perceived risk was operationalized as consumers perceived and their own tolerance of risk-taking that influences their financial transaction decision that is similar to (Jarvenpaa, Tractinsky, and Vitale, 2000; Lai and Zainal, 2015). In this study, a 5 point Likert scale of measurement the perceived risk in Table 1 is adapted from Jarvenpaa, Tractinsky, and Vitale (2000), Chan and Lu (2004), Ndubisi and Sinti (2006) and Lai and Zainal (2015).

\section{Consumers' Intention to Use}

According to Davis, Bogozzi, and Warshaw (1989), consumers' intention to use was operationalized as an integrated single platform E-payment System platform system for Card, Internet and Mobile Payment known as the novelty single platform E-payment for consumers' to use which is similar to Lai (2014: 2016: 2017: 2018). The measurement of behavior intention to use was adapted from Davis, et al., (1989) as well as Lai (2014: 2016: 2017; 2018) using a 5 point Likert scale. Table 1 below shows the compilation of the measurements used in this research. 


\section{DATA ANALYSIS}

The measurement procedures and related operational definitions used to define the research methodology are directly dependent on the accuracy and quality of the data collected from the research. Marczyk, DeMatteo, and Festinger (2005) noted that reliability and validity are the most common and important psychometric concepts related to assessment-instrument selection and other measurement strategies. The data collected from the survey used Structured Equation Modelling (SEM) for analysis.

The empirical data was analyzed using SPSS version 22 to obtain common descriptive statistics such as frequency and percentage to describe the demographic characteristics of the respondents. Cronbach's Alpha was used to ensure that variables in each construct were internally consistent. Factor analyses were employed to validate the dimensions of independent variables and dependent variable. As usual, frequencies, percentages, maximum, minimum, means, standard deviations, and intercorrelations of the variables were also calculated.

\section{Reliability}

Yin (2002) expressed that reliability is the degree to which measures are considered free from random error. Reliability is concerned with the consistency or stability of the score obtained from a measure or assessment technique over time and across settings or conditions (Anastasi and Urbina, 1997; White and Saltz, 1957). Therefore, regarding the reliability concept for this research, and knowing the acceptance and generalization of Cronbach's coefficient alpha $(\alpha)$, this research tried to address internal consistency by asking different related questions on the subject of every single dimension. Every effort was made to ensure that data was collected, recorded, compiled, and analyzed accurately. According to Leary (2004), the data entry should be closely monitored and audits should be conducted on a regular basis for reliability. The researcher used the Cronbach's Alpha value to assess the reliability of the items. The rule of assessment is according to George and Mallery (2005) in Table 2.

Table 2. Cronbach's Alpha Rules

\begin{tabular}{lc}
\hline Cronbach's Alpha & Rules \\
\hline Cronbach's Alpha $\leq 0.5$ & Unacceptable \\
$0.5<$ Cronbach's Alpha $\leq 0.6$ & Poor \\
$0.6<$ Cronbach's Alpha $\leq 0.7$ & Questionable \\
$0.7<$ Cronbach's Alpha $\leq 0.8$ & Acceptable \\
$0.8<$ Cronbach's Alpha $\leq 0.9$ & Good \\
Cronbach's Alpha $>0.9$ & Excellent \\
\hline
\end{tabular}

Source: George and Mallery (2005)

\section{Validity}

Validity indicates whether the measures used are accurate constructs describing the event. Churchill (1979) recommended establishing content validity in the early stages of research. Therefore, the scale items for each construction were screened by experts in the design and analysis of the 
statistical surveys to examine the study instruments. Construct validity (Hair, Wolfinbarger, Ortinau, and Bush, 2008) was performed after the content validity to determine the extent to which the operational construct of each actually measured what it was supposed to measure. In this study, construct validity and statistical validity are used as well. Statistical validity addresses the question of whether the statistical conclusions drawn from the results of a study are reasonable (Graziano and Raulin, 2004).

\section{Mean and Standard Deviations}

In this study, the statistical approach for determining equivalence between groups is to use simple analyses of means and standard deviations for the variables of interest for each group. Basically, mean is an average score, and a standard deviation is a measure of variability indicating the average amount that scores vary from the mean (Marczyk, DeMatteo and Festinger, 2005).

\section{Pilot Study}

Participation by the respondents was purely voluntary. The 30 set of questionnaires designed for pilot study were distributed to academics, students and relevant experts in the field of Information Communication Technology, Telecommunications and Finance before the final version being put online to collect the actual data. The academicians, students and relevant experts in the field of Information Communication Technology, Telecommunications and Finance were selected for the pilot study because they're expected to represent the biggest group of participants in this the novelty single platform E-payment research survey. Information Communication Technology, Telecommunications, and Finance are selected because these groups were the target pioneer users. Respondents' feedbacks of the questionnaires were straightforward and relevant.

The pilot study provided good feedback with high overall Cronbach’s alpha as shown in Table 3.

Table 3. Pilot Study Cronbach’s Alpha

\begin{tabular}{lccc}
\hline Dimension & Items & Scale & Cronbach's $\boldsymbol{\alpha}$ \\
\hline Consumers' Intention to use & 4 & $1-5$ & .92 \\
Perceived Usefulness & 10 & $1-5$ & .96 \\
Perceived Ease of Use & 10 & $1-5$ & .91 \\
Perceived Risk & 6 & $1-5$ & .88 \\
Design & 8 & $1-5$ & .89 \\
Convenience & 6 & $1-5$ & .94 \\
\hline
\end{tabular}

\section{Descriptive Statistics}

Descriptive statistics are being used to identify the basic characteristics of the data in a research (Emory and Cooper, 1991). In this study, the SPSS version 22 was used to perform the descriptive statistics such as mean and standard deviations as well as frequencies and percentages for respondents' profile after the collected data are entered. The respondents' profiles were run based on these categories namely, age, gender, marital status, industry, education, position, living area, items 
10 Lai, P.C.

owned and consideration of using the novelty single platform E-payment. The mean for overall variables was also being run with a minimum scale of 1 and a maximum scale of 5 where the highest level of agreement was "strongly agree" denoted by a scale value of 1 and "strongly disagree" denoted by a scale value of 5 .

\section{GOODNESS OF MEASURES}

According to Mayers, Gamst, and Guarino (2006), the goodness of measures objective is to ascertain the factors or construct underlying the relatively set of variables. In this section, factor analysis was performed using SPSS version 22 to check whether the items were correlated to each other as they measured the variables. A group of items was required to explain one variable as one item denotes only one part of the variable..

The factor analysis consists of two steps, namely extracting the items and rotating the items using the principal component factor analysis with varimax rotation. This process reveals the items that contribute to a factor that a frame of an element and rotation process refers to the interpretations that determine a simpler and more significant factor. As suggested by Kim and Mueller (1978), there should be at least three items for each construct with the minimum significant loading of \pm .30 that indicates only $10 \%$ of the variance is accounted for by the factors, while \pm .40 loading is more vital; at \pm .50 the loading is more significant and above \pm .70 explains $50 \%$ of the variances. As the rule of thumb suggested by Hair et al.(2006), the significant loading should be .50 or higher.

Kaiser-Meyer-Olkin (KMO) measure of sampling adequacy is an index used to examine the appropriateness of factor analysis that should be more than .50 in order to be acceptable according to (Hair et al., 2006). Bartlett's test of sphericity is a test statistic used to examine the hypothesis that the variables are uncorrelated in the population. In other words, the population correlation matrix is an identity matrix; each variable correlates perfectly with itself $(r=1)$ but has no correlation with the other variables $(r=0)$ (Malhotra, 2009).

\section{Correlation Analysis}

The correlation design of this study has the ability to explain the relationship between a set of consumers behavior intention to use the novelty single platform E-payment factors. Vogt (2007) suggested that the correlation technique is helpful to determine if, and to what extent, a relationship exists between two variables. Furthermore, correlation analysis doesn't need to have a control group and an experimental group to find causes and effects.

The Pearson Correlation Analysis is used to show the strength of the association between the variables involved. Inter-correlations coefficients (r) are calculated by means of Pearson's Product Moment. A correlation coefficient has a value of -1 to +1 . A zero value means that there is no relationship between the two variables. $R$ of $>0.8$ indicates a high correlation between the two variables (Sekaran, 2003).

\section{Structural Equation Modeling (SEM)}

This research aims to generate an adapted model of Technology Acceptance that best describe the consumers' intention to use the novelty single platform E-payment in Malaysia. Therefore, Structural Equation Modeling is considered to be the most suitable as the produced model is expected 
to be a model that is both substantively meaningful and statistically well-fitting (Jöreskog, 1971; Bryne, 2006).

Structural Equation Modelling (SEM) is a multivariate technique combining aspects of multiple regression (examining dependence relationships) and confirmatory factor analysis (representing unmeasured concepts-factors with multiple variables) to estimate a series of interrelated dependence relationships simultaneously (Hair, Black, Babin, Anderson and Tatham, 2010; Schumacker and Lomax, 1996). In addition, SEM is also known as path analysis with latent variables and is now a regularly used method for representing dependency (arguably "causal”) relations in multivariate data in behavioral and social sciences (McDonald and Ho, 2002). Therefore, this study uses Structural Equation Modelling (SEM) because SEM can be used to analyze the theoretical model that consists of direct (and indirect) relationships between the independent variables and dependent variables.

\section{Confirmatory Factor Analysis (CFA)}

Raykov and Marcoulides (2006) noted that Confirmatory Factor Analysis was potentially correlated with one another and had no specific directional relationships between the constructs. Confirmatory Factor Analysis (CFA) in this study was performed on the five independent variables perceived usefulness, perceived ease of use, perceived risk, design, and convenience. The independent variables consisted of 40 items. Likewise, confirmatory factor analysis was conducted to check the dimensionality of the dependent variable (i.e. consumers' intention to use the novelty single platform E-payment). Furthermore, the use of confirmatory factor analysis by SEM reduced errors each latent variable that had multiple indicators.

CFA was verified using the Kaiser-Meyer-Olkin (KMO) Measure of Sampling Adequacy and Bartlett's test of sphericity. The Kaiser-Meyer-Olkin (KMO) measure of sampling adequacy is an index used to examine the appropriateness of factor analysis. High values (between 0.5 and 1.0) indicate factor analysis is appropriate. Values below 0.5 imply that factor analysis may not be appropriate. Bartlett's test of sphericity is a test statistic used to examine the hypothesis that the variables are uncorrelated in the population. In other words, the population correlation matrix is an identity matrix; each variable correlates perfectly with itself $(r=1)$ but has no correlation with the other variables $(r=0)$ (Malhotra, 2009).

\section{Goodness of Fit}

Based on SEM, the overall fit model for the final measurement model was estimated to ensure a good data fit. The five absolute fit indices (Good-of-fit): $\chi^{2}$ goodness-of-fit statistic, $\chi^{2} / \mathrm{df}$, Goodness of Fit (GFI), Comparative Fit Index (CFI), Tucker-Lewis Index (TLI), and Standardized Root Mean Square Error of Approximation (RMSEA) will be assessed.

Absolute fit indices are meant to measure how well the proposed model reproduced the observed data and provides the most basic assessment of how well a researcher's theory fits the sample data. The $\chi^{2}$ goodness-of-fit statistic may be insignificant but the p-value significant can be expected (Klien, 2011). The relative Chi-Square ( $\chi 2 / \mathrm{df})$ is very good if the value is below 5.0 (Tabachnick and Fidell, 2007). As for GFI, an only guideline to fit is required as no statistical test is associated with the GFI. The possible range of GFI values is 0 to 1 , with higher values indicating a better fit but according to Hair et al (2010), GFI should be more than 0.90. The comparative fit index (CFI) should be above the 0.90 (Hu and Bentler 1999) and according to McDonald and Ho (2002), root means square error of 
12 Lai, P.C.

approximation (RMSEA) should be smaller than 0.08 to be considered a good fit. Klien (2011) noted that TLI value should be greater than 0.90 . A summary of the goodness of fit indices acceptance level for the measurement and structural model are as shown in Table 4.

Table 4. Goodness of Fit Indices Acceptance Level

\begin{tabular}{lcc}
\hline $\begin{array}{l}\text { Goodness-of-fit } \\
\text { Statistics }\end{array}$ & Level of Acceptance \\
\hline $\begin{array}{l}\text { Absolute fit Measures } \\
\text { Chi-square }\end{array}$ & $\mathrm{X}^{2}$ & $p>0.05$ \\
$\begin{array}{l}\text { Degree of freedom } \\
\text { Root mean square error of approximation }\end{array}$ & $\mathrm{df}$ & $\geq 0$ \\
& RMSEA & $<0.08$ \\
$\quad$ Goodness of fit index & GFI & $>0.90$ \\
$\begin{array}{l}\text { Incremental fit measures } \\
\quad \text { Comparative fit index }\end{array}$ & CFI & $>0.90$ \\
Parsimonious fit measures & & $<5$ \\
$\quad$ Relative Chi-Square & $\mathrm{X}^{2 / \mathrm{df}}$ & \\
\hline
\end{tabular}

Sources: Byrne (1998), McDonald and Ho (2002), Tabachnick and Fidell (2007), Hair (2010) and Kline (2011), Lai (2014: 2016: 2017; 2018)

\section{Measurement and Structural Model}

According to Anderson and Gerbing (1988), a two-step approach is suggested rather than a single-step approach in SEM. This research uses the two-step approach to SEM, namely a measurement model and a structural model (Hair, Black, Babin, and Anderson 2010). Firstly, the measurement models are evaluated to ensure that the items used to measure each of the constructs is adequate. The second step is the measurement model also involves conducting CFA to assess the contribution of each indicator variable and to measure the adequacy of the measurement model. This includes the validity of each item in each of the six (6) measurement model of design, convenience, perceived usefulness, perceived ease of use, perceived risk and consumers' intention to use the novelty single platform E-payment. For example, the measurement model of design has 8 items, if the factor loading of an item $<.05$, the item will be removed from the measurements model. This shall be applied to the rest of the measurement model. As for construct validity of each measurement model, Goodness of Fits in Table 4 will be referred.

Structural Model of the study is to represent the relationship among the variables in the theoretical framework. Structural Model will be developed after CFA and Goodness of Fits. SEM will be used to identify the validity of the structural model of the study.

\section{Construct Validity and Construct Reliability}

Construct validity can be assessed by considering construct reliability, factor loadings, and variances extracted. As suggested by Hair et al., (2006), the factor loadings in the measurement model 
should be significant and .50 or higher, and ideally .70 or higher as the criteria for construct validity. The rational for the .70 or higher is that a loading of .71 squared equals .50 which means that the factor explains at least half of the variation in the item.

The average variance extracted (AVE) percentage should be .50 or higher and is calculated as follows:

$n$

$$
\sum \lambda_{12}
$$

$$
A V E=\overline{i=1 n}
$$

Where:

$\lambda=$ standardized factor loading $n$

$=$ the number of items

In the formula above the $\lambda$ represents the standardized factor loading and $i$ is the number of items. So, for $n$ items, AVE is computed as the sum of the squared standardized factor loadings divided by the number of items, as shown above. A good rule of thumb is an AVE of .50 or higher indicates adequate convergent validity. An AVE of less than .50 indicates that on average, there is more error remaining in the items than there is variance explained by the latent factor structure you have imposed on the measure. An AVE estimate should be computed for each latent construct in a measurement model.

The measure of reliability and internal consistency of the measured variables representing a latent construct and the Construct Reliability (CR) should be $\geq .60$ (Hair et al., 2010) to achieve convergent validity. The formula used to calculate the construct reliability value in a measurement model is as follow:

$$
\mathrm{CR}=\frac{\left(\sum \lambda\right)^{2}}{\left(\left(\sum \lambda\right)^{2}+\left(\sum 1-\lambda^{2}\right)\right)}
$$

$\lambda=$ standardized factor loading of every item;

The extent to which a construct is extremely distant from other construct is known as discriminant validity according to Hair et al., (2010). Thus, each measured items should only represent one latent construct. Therefore, the measurement model will be free from redundant items. CFA offers two methods to assess discriminant validity. The first method recommended by Bagozzi and Phillips (1982) involves a Chi-square difference analysis between a nested CFA model where the correlation between the two constructs is constrained. The second method was suggested by Bagozzi, Yi, and Phillips (1991) by examining the confidence interval for the estimated correlation between two constructs at the 95\% confidence interval. Therefore, the discriminant validity is achieved when the correlation between any two constructs is significant from unity with the cut-off value of .90 according to Hair et al. (2010).

\section{CONCLUSION}

This article introduced the methodology and deliberated the details of research instrument development for novelty technology, namely the novelty single platform E-payment. This article also 
14 Lai, P.C.

discussed the subjects, population, sample size requirement, data collection method and measurement of variables, pilot study and statistical techniques for data analysis. In this article also particular, focus on Structural Equation Modeling analysis. Figure 2 showed the overview of the research methodology using structural equation modeling analysis of the article Lai (2014: 2016: 2017; 2018) being conducted.

The section starts with literature review to identify the gap in the literature and the problems that form the research questions, objectives, research model and hypothesis. Then, the initial questionnaire was developed with revision in the questionnaire design section before the pilot study was done. A pilot study was conducted by surveying 30 respondents to check the reliability and validity analysis before the final questionnaire was distributed for the main study. The data collection underwent the test measurement model (confirmatory factor analysis) and test structural model (Structural Equation Modeling) during the analysis process. Then, the results were presented with theoretical and management implications.

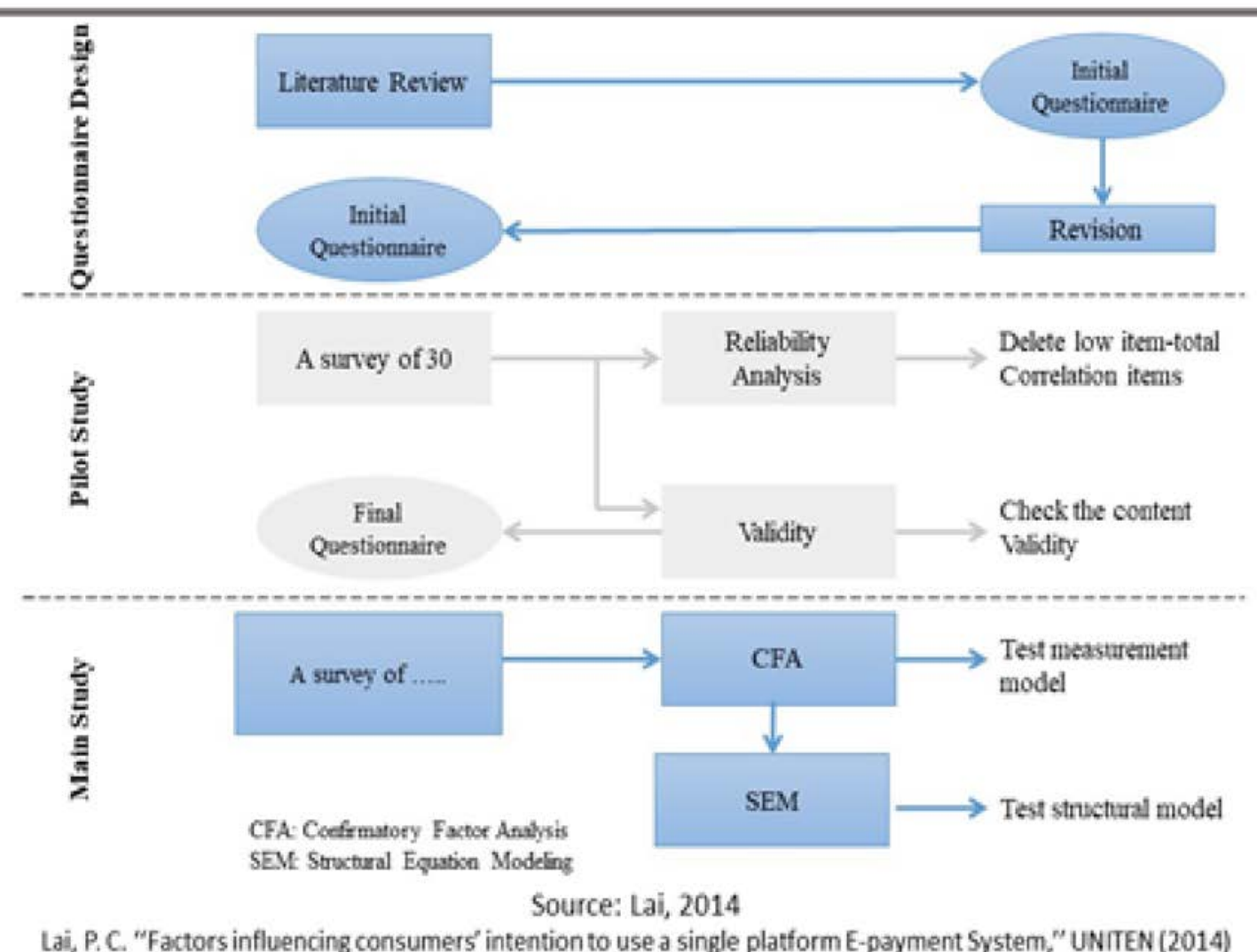

Lai, P. C. "Factors influencing consumers' intention to use a single platform E-payment System," UNITEN (2014)

Figure 2. Overview of research Methodology (Lai, 2014)

It is hoped that the review sheds some light and potential applications for future researchers, students and others to conceptualize, operationalize and analyze the underlying research methodology to assist in the development of novelty technology. 


\section{REFERENCES}

Avison, D. E., \& Fitzgerald. G. (1995). Information systems development: methodologies, techniques, and tools. London: McGraw-Hill.

Anastasi, A., \& Urbina, S. (1997). Psychological testing (7th ed.). Englewood Cliffs, NJ: Prentice Hall.

Anderson, J. C., \& Gerbing, D. W. (1988). Structural Equation Modelling in practice: a review and recommended two-step approach. Psychological Bulletin, 103 (3), 411-423.

Byrne, B. M. (1998). Structural Equation Modeling with LISREL, PRELIS, and SIMPLIS: Basic Concepts, Applications, and Programming. New Jersey: Lawrence Erlbaum Associates.

Bryman, A., \& Bell, E. (2007). Business Research Method, 2nd ed. Oxford: Oxford University Press.

Chan, S. C., \& Lu T. M. (2004). Understanding Internet Banking Adoption and Use behaviour: A Hong Kong perspective. Journal of Global Information Management, 12, 3 12-43.

Churchill, G.A. (1979). A paradigm for developing better measures of marketing constructs. Journal of Marketing Research, 16, 64-73.

Cohen, P.N. (1998). Black concentration effects on black-white and gender inequality: Multilevel analysis for US metropolitan areas. Social Forces, 77(1), 207-229.

Cooper, D. R., \& Schindler, P. S. (2008). Business research methods (10th ed.). New York: McGraw-Hill.

Crotty, M. (1998) The Foundations of Social Research: Meaning and Perspective in the Research Process, London: Sage Publications.

Cox, E. P., (1980). The optimal number of response alternatives for a scale: A review. Journal of Marketing Research, 17, 407-422.

Davis, F. D. (1989) Perceived usefulness, perceived ease of use, and user acceptance of information technology. MIS Quarterly, 13(3), 319-340.

Davis, F. D., Bogozzi, R., P., \& Warshaw, P., R. (1989). User acceptance of computer technology: A comparison of two theoretical models. Management Science, 35, 982-1003.

Emory, W C., \& Cooper. D. R. (1991). Business Research Methods, 4th edition, Homewood, IL: Richard D. Irwin.

George, D. \& Mallery, P. (2003). SPSS for Windows step by step: A simple guide and reference. 11.0 update (4th ed.). Boston: Allyn \& Bacon.

Graziano, A. M., \& Raulin, M. L. (2004). Research methods: A process of inquiry (5th ed.). Boston: Allyn \& Bacon.

Hair, J. F., Wolfinbarger, M., Ortinau, D. \& Bush, R. (2008). Essentials of Marketing Research. New York:McGraw Hill/Irwin.

Hair, J. F. (2010). Multivariate data analysis: a global perspective. Upper Saddle River, New Jersey, USA: Person Prentice Hall.

Hair, J., Black, W., Babin, B. Y. A., Anderson, R., \& Tatham, R. (2010). Multivariate Data Analysis (7th ed.). New Jersey: Pearson Prentice Hall.

Harrison, R., Scheela, W, P C, Lai, Vivekarajah, S. Beyond institutional voids and the middle income trap? The emerging business angel market in Malaysia, Asia Pacific Journal of Management. September 2017, $1-27$.

Hu, L., \& Bentler, P. M. (1999). Cutoff criteria for fit indexes in covariance structure analysis: Conventional criteria versus new alternatives. Structural Equation Modeling: A Multidisciplinary Journal, 6(1), 1-55 
16 Lai, P.C.

Jarvenpaa, S. L., Tractinsky, N., \& Vitale, M. (2000). Consumer trust in an internet store. Information Technology and Management, 1(1/2), 45-71.

Jöreskog, K. G. (1971) Simultaneous factor analysis in several populations, Psychometrika, 36, 409-26.

Jöreskog, K. G. (1993). Testing structural equation models, In Byrne, B. M. (2006). Structural Equation Modeling with EQS: basic concepts, applications, and programming 2nd edn, Mahwah, New Jersey, Lawrence Erlbaum Associates, Inc.

Kim, J. O., \& Mueller, C. W., (1978). Introduction to factor analysis: What it is and how to do it. Beverly Hills, CA: Sage

Kline, R. B., (2011). Principles and practice of structural equation modelling (3rd ed.). New York: Guilford Press.

Krejcie, R., and Morgan, D. W., (1970). “Determining Sample size for Research Activities”. Educational and Psychological Measure, 30, 607-610.

Lai P. C (2006). The significant of E-business and knowledge-based Customer Relationship in the E-market Place Environment. INTI Journal, 2 (1) 552-559.

Lai, P. C. (2007). The Chip Technology Management Implication in the Era of Globalization: Malaysian Consumers’ Perspective, Asia Pacific Business Review, 3(1), 91-96

Lai P. C. (2010). E-business and E-banking. Japan Society for Software Science and Technology, Itech research group.

Lai P. C. (2012). E-Payment Systems Services. E-payment Banking. GlobalCLAS

Lai, P. C. (2014). Factors influencing Consumers' intention to use single platform E-payment. UNITEN

Lai P. C. \& Ahmad, Z. A. (2015). Perceived Enjoyment and Malaysian consumers' intention to use a single platform E-payment. SHS Web o f Conferences, 18, EDP Sciences

Lai P. C. \& Zainal A. A., (2015). Consumers’ Intention to Use a Single Platform E-Payment System: A Study Among Malaysian Internet and Mobile Banking Users. Journal of Internet Banking and Commerce. (20)

(1) $1-13$

Lai P. C. \& Zainal A.A, (2015). Perceived Risk as an Extension to TAM Model: Consumers' Intention To Use A Single Platform E-Payment. Australia Journal Basic and Applied Science, 9(2): 323-330.

Lai, P. C. (2016) Design and Security impact on consumers' intention to use single platform E-payment, Interdisciplinary Information Sciences, 22 (1), 111-122

Lai, P. C. (2017). The literature review of technology adoption models and theories for the novelty technology. Journal of Information Systems and Technology Management, 14 (1), Jan/Apr., 21-38

Lai P C, Scheela, W, Convergence of technology in the E-commerce World and Venture Capital Landscape: South East Asia, Global Entrepreneurship and New Venture Creation in the Sharing Economy. IGIGlobal, 2018, 149-168

Lai, P. C. (2018), Single platform E-payment Consumers' intention to use. Journal of Information Technology Management. 29 (2), 22-28

Lai, P. C. (2018), Security as an extension to TAM Model: Consumers' intention to use a single platform Epayment System. Asia Pacific Journal of Management Research and Innovation 13 (3-4), 110-119

Lai P C. (2018) Research, Innovation and Development Strategic Planning for Intellectual Property Management. Economic Alternatives 12 (3), 303-310

Laukkanen, T., \& Lauronen, J. (2005). “Consumer value creation in mobile banking services”. International Journal of Mobile Communications, 3 (4), 325 - 338. 
Leary, M. R. (2004). Introduction to behavioral research methods. Boston: Allyn \& Bacon

Lin, J. and Hsieh, P., (2006). The role of technology readiness in customers' perception and adoption of selfservice technologies, International Journal of Service Industry Management, 17, 497-517

Marczyk G., DeMatteo D., \& Festinger D. (2005). Essentials of Research Design and Methodology, John Wiley \& Sons, Inc.

Malaysia, Bank Negara Financial Stability and Payment systems report 2007-2013.

Malaysia, The 2010 Population and Housing Census of Malaysia (Census 2010)

Malhotra, N. (2009). Marketing Research: An Applied Orientation with SPSS (6ed). Pearson Education.

Maran, M., Lawrence, A., M. Fazilah, A. S., M. Kishna, M., and Ng, K. K. (2011) “'Cashless Society and the determinants: An empirical Investigation,’’ International Journal of Academic Research, 3(3), 674-682.

Maylor, H., \& Blackmon, K. (2005). Researching Business and Management. New York: Palgrave Macmillan.

McDonald, R. P., \& Ho, M-H, R. (2002). Principles and Practice in Reporting Structural Equation Analyses. Psychological Methods, 7(1), 64-82.

Meyers, L. S., Gamst, G., \& Guarino, A. J. (2006). Applied multivariate research. Sage publications: London.

Meuter, M. L., Ostrom, A. L., Roundtree, R. I., \& Bitner, M. J. (2000). Self-service technologies: Understanding customer satisfaction with technology-based service encounters. Journal of Marketing, 64(3), 50-65.

Miller, D. (1983). Handbook of Research Design and Social Measurement, 4th ed. London: Longman.

Neuman, W. (2006). Social research methods: Qualitative and quantitative approaches (6th ed.). Needham Heights, MA: Allyn \& Bacon.

Ndubisi, N.O. and Sinti, Q., (2006). Consumer attitudes, system's characteristics and internet banking adoption in Malaysia. Management Research News, 29 (1/2), 16-27.

Oppenheim, A.N., (1992). Questionnaire design, interviewing and attitude measurement. 2nd ed. London and New York: Continuum International Publishing.

Harrison, R., Scheele, W., Lai, P. C., Vivekarajah S, (2017). Beyond institutional voids and the middleincome trap: The emerging business angel market in Malaysia. Asia Pacific Journal of Management, 1-27

Raykov, T., \& Marcoulides, G. A. (2006). Estimation of Generalizability Coefficients via a Structural Equation Modeling Approach to Scale Reliability Evaluation, International Journal of Testing (6), 81-95.

Saunders, M., Lewis, P. \& Thornhill, A. (2016). Research methods for business students. $7^{\text {th }}$ Edition, Pearson Education Ltd.

Schumacher, R. E., \& Lomax, R. G. (1996). A Beginner’s Guide to Structural Equation Modeling. New Jersey: Lawrence Erlbaum Associates, Publishers

Sekaran, U. (2003), Research Methods for Business. 4th ed. U. S. A.: John Wiley and Sons, Inc

Sekaran, U. \& Bougie, R. (2013), Research Methods for Business: A Skill-Building Approach. 7th ed. U. S. A.: John Wiley and Sons, Inc.

Szymanski, D.M., \& Hise, R.T. (2000). E-satisfaction: An initial examination. Journal of Retailing, 76(3), 309-322.

Tabachnick, B. G., \& Fidell, L. S. (2007). Using Multivariate Statistics. Boston: Pearson Education Inc. Vogt, W. P. (2007). Quantitative research methods for professionals. Boston, MA: Pearson Education. White, B. W., \& Saltz, E. (1957). Measurement of reproducibility. Psychological Bulletin, 54, p. 81-99. 
18 Lai, P.C.

Wortley, D. J., Lai, P. C., (2017) The Impact of Disruptive Enabling Technologies on Creative Education, 3rd International Conference on Creative Education, Mar 3-4

Yin, R. (2002). Case Study Research, Design and Methods. (3rd ed), Newbury Park: Sage Publications. 